\title{
CONTROLE CONCENTRADO DE CONSTITUCIONALIDADE NO BRASIL: ANÁLISE JURISPRUDENCIAL DA ADPF 635
}

\section{RESUMO}

Rafael Pinto dos Santos*1

O presente estudo objetiva uma análise do controle concentrado de constitucionalidade no Brasil em especial a Arguição de Descumprimento de Preceito Fundamental de número 635, de relatoria do ministro Edson Fachin. A problemática do trabalho consiste em averiguar se a supracitada ação, durante a pandemia do novo coronavírus, demonstra-se suficiente para proteger os direitos fundamentais da população residente em áreas carentes do RJ no decorrer de confrontos entre policiais e traficantes. Os resultados alcançados evidenciaram que a decisão proferida pelo STF promoveu efeitos benéficos à sociedade carioca. O método de estudo a ser utilizado pode ser compreendido como bibliográfico-documental.

Palavras-chave: Controle de constitucionalidade. ADPF. Preceitos fundamentais. Direitos fundamentais. Confrontos.

\section{CONCENTRATED CONTROL OF CONSTITUTIONALITY IN BRAZIL: ADPF JURISPRUDENTIAL ANALYSIS NO. 635}

\begin{abstract}
:
The present study aims to analyze the concentrated control of constitutionality in Brazil, especially the Claim of Non-compliance with Fundamental Precept, number 635, reported by Minister Edson Fachin. The problem of the work is to investigate whether the aforementioned action, during the new coronavirus pandemic, proves to be sufficient protect the fundamental rights of population residing in poor areas of RJ during confrontations between police and drug dealers. The results achieved showed that the decision handed down by the STF promoted beneficial effects to the society of RJ. The study method to be used can be understood as bibliographic-documentary.
\end{abstract}

Keywords: Control of constitutionality. ADPF. Fundamental precepts. Fundamental rights. Confrontations.

\section{INTRODUÇÃO}

O presente estudo possui o objetivo de efetuar uma abordagem acerca da Arguição de Descumprimento de Preceito Fundamental - ADPF, considerada uma medida processual em defesa do texto constitucional de 1988, para, em seguida, realizar a análise jurisprudencial da ADPF 635, do Superior Tribunal Federal, ajuizada em novembro de 2019, obtendo como

\footnotetext{
${ }^{1}$ Mestre em Direito pelo Centro Universitário Salesiano de Lorena (UNISAL). Docente de Direitos Humanos e Direito Administrativo na Academia Militar das Agulhas Negras (AMAN). E-mail: rjanjo72@yahoo.com.br
} 
relator o Ministro Edson Fachin. Nesse sentido, a pesquisa almeja responder a seguinte pergunta: a ADPF 635 consistiu em avanço ou retrocesso na salvaguarda dos direitos fundamentais da população residente em áreas de confronto no Rio de Janeiro?

A fim de alcançar o objeto proposto, o trabalho inicialmente abordou os sistemas de controle de constitucionalidade, quais sejam: difuso e concentrado, para, posteriormente, analisar o sistema aplicado no Brasil, a fim de preparar o leitor para a análise posterior da Arguição de Descumprimento de Preceito Fundamental no ordenamento pátrio. A referida ação reflete a consolidação do controle concentrado de constitucionalidade em detrimento ao controle difuso no Brasil, uma vez que o país adota o sistema misto.

Em seguida, almejou-se examinar o teor da sentença "preceito fundamental", a fim de verificar como ocorre sua conceituação na doutrina e na jurisprudência brasileiras e o debate que circunda entre o que se considera ou não preceito fundamental. Por último, a pesquisa empenhou-se em constatar os efeitos ocasionados por uma ADPF, no caso a de número 635, quando o Ministro Edson Fachin, no ano 2020, deferiu liminar para afastar novas operações policiais em comunidades carentes do Rio de Janeiro, mediante sanção de responsabilização civil e penal, exceto em casos excepcionais e mediante documento informativo ao Ministério Público do Rio de Janeiro.

Como resultados, o trabalho retratou que os dados apresentados por Hirata et. al. (2020) demonstraram efeitos positivos na proteção do direito à vida e à integridade física dos moradores envolvidos nas operações realizadas no Rio de Janeiro, à medida que houve a redução da violência armada no estado e menores índices de óbito após a supracitada decisão.

Baseando-se nas características de uma pesquisa bibliográfica e descritiva que foi empregada para sustentar cientificamente os objetivos do estudo. Com uma didática de cunho exploratório, o trabalho realiza um levantamento bibliográfico, buscando reunir os esclarecimentos sobre o tema com o propósito de identificar os assuntos relevantes que forneçam uma sustentação aos argumentos elencados.

\section{SISTEMAS DE CONTROLE DE CONSTITUCIONALIDADE}

A Constituição, considerada a principal norma de um país, denota orientações singulares ao Estado, indicando o gerenciamento de sua ação e a interação com a população, 
assegurando os direitos essenciais do indivíduo, devendo ser interpretada e reverenciada como uma norma fundamental. O exame da constitucionalidade ocorre, primeiramente, mediante o controle de constitucionalidade ordenado na Lei Maior, a qual afere competência a um ou mais órgãos para exercê-la de forma política ou jurisdicional, interna ou externamente ao Poder Judiciário.

O controle de constitucionalidade é característico das Constituições rígidas, na qual há um procedimento mais solene para alterá-las. Entretanto, também é plausível a existência de verificação no que corresponde à conformidade de normas com as Constituições flexíveis, tendo em vista que, ainda em tais textos, poderão ocorrer violações e desrespeitos as suas disposições elementares, como, por exemplo, se contrariar o procedimento ou a competência do órgão para a elaboração de leis, ocasionando, assim, uma inconstitucionalidade.

Pode-se afirmar que duas são as categorias prevalecentes atualmente em sede de controle de constitucionalidade da legislação nas Cortes Constitucionais, quais sejam: o modelo difuso, que obteve sua manifestação nos Estados Unidos da América em 1803, através do caso Marbury versus Madison; e o tipo concentrado, que adquiriu sua primeira expressão no texto constitucional austríaco, no final do século XIX, inspirado pelos estudos do jurista alemão Hans Kelsen. (NOVELINO, 2008, p. 89)

O modelo difuso se revela presente onde o exercício do controle de constitucionalidade recai a todos os órgãos do Poder Judiciário, incidentalmente, quando da deliberação de casos concretos de sua atribuição. O mencionado sistema também é anunciado como o modelo americano, por conta da previsão no ordenamento jurídico dos EUA acerca da observância do texto constitucional por todos os magistrados, mesmo que leis infraconstitucionais afiram em percepção diversa.

Nessa sistemática, o juiz possui autonomia para não aplicar uma norma ordinária quando esta divergir com a Carta Política, pois se emprega o critério lex superior derrogat inferiori, de maneira que o texto constitucional prepondera sobre a lei ordinária em divergência. O modelo difuso, ainda, possui como particularidade a preservação da liberdade dos magistrados na tutela da Lei Maior, propiciando ao Poder Judiciário, especialmente à Suprema Corte, a incumbência de proteger a Constituição, não somente no que diz respeito à repartição de poder entre os Estados-Membros e a Federação, como também perante à atuação dos Poderes, sobretudo o Legislativo. (CUNHA JÚNIOR, 2004, p. 406)

Dessa forma, as lições de Barroso (2012, p. 83) revelam que: 
O controle incidental de constitucionalidade é um controle exercido de modo difuso, cabendo a todos os órgãos judiciais indistintamente, tanto de primeiro como de segundo grau, bem como aos tribunais superiores. Por tratar-se de atribuição inerente ao desempenho normal da função jurisdicional, qualquer juiz ou tribunal, no ato de realização do Direito nas situações concretas que lhes são submetidas, tem o poder-dever de deixar de aplicar o ato legislativo conflitante com a Constituição. Já não se discute mais, nem em doutrina nem na jurisprudência, acerca da plena legitimidade do reconhecimento da inconstitucionalidade por juiz de primeiro grau, seja estadual ou federal.

A vertente americana possui como peculiaridade o consentimento de que todo e qualquer magistrado ou tribunal possa desempenhar na hipótese factual a análise sobre a harmonia de norma infraconstitucional com a Constituição. Dessa feita, debate-se o caso real, motivo pelo qual as decorrências do julgamento refletem exclusivamente entre os sujeitos participantes do processo.

Por outro lado, o modelo concentrado é aquele que defere a constatação de constitucionalidade a um órgão específico, o Tribunal ou Corte Constitucional, instituído apenas para tal escopo, não necessariamente relativo ao Poder Judiciário. Em consonância com as observações de Favoreu (2004, p. 223) a Corte Constitucional é considerada uma “jurisdição elaborada para conhecer exclusiva e especialmente o contencioso constitucional, situada externamente ao aparelho constitucional ordinário, sendo independente deste e ainda dos Poderes Públicos".

As aludidas instituições possuem o privativo encargo de inspecionar a constitucionalidade das normas e dos atos dos poderes do Estado, reforçando, extremamente, a supremacia constitucional. O modelo em comento também é intitulado de sistema austríaco, pois foi delineado e concretizado na Constituição Austríaca de 1920. (STRECK, 2019, p. 69)

Um atributo fundamental desse sistema é que, como o texto constitucional não se restringe a enunciar o direito, a "aferir uma ordem", e sim a estipular "diretrizes e programas dinâmicos de ação posterior", o controle de constitucionalidade seria mais apropriado se executado por um órgão específico, pois, nessa circunstância, a guarda da Lei Maior é um encargo mais legislativo e político do que jurisdicional. Não sendo, assim, uma atividade pertinente aos togados comuns.

Nesse sentido, as lições de Ramos (2010, p. 112):

O modelo europeu (austríaco ou kelseniano) é afamado como o controle por via principal, porquanto a declaração de inconstitucionalidade da lei ou do ato normativo é feita objetivando alcançar a invalidação da lei para firmar a segurança das relações jurídicas. Logo, ao contrário do sistema difuso, declarada a 
inconstitucionalidade da norma no sistema abstrato (onde discutem-se teses, que resultam em teorias, e não decisões) e concentrado (onde a decisão é tomada em única instância), isto é, em processo objetivo e não subjetivo, por não haver partes envolvidas no litígio, a decisão irradia-se por automatismo (eficácia erga omnes).

Logo, cumpre ressaltar que o sistema brasileiro teve, inicialmente, a influência norteamericana e, posteriormente, passou a empregar juntamente o sistema austríaco, isto é, concentrado e difuso em vista da lacuna encontrada em um ou outro modelo, separadamente. Tal posição é adotada por Moraes (2017, p. 524): "No Brasil, o controle de constitucionalidade repressivo judiciário é misto, ou seja, é exercido tanto da forma concentrada, quanto da forma difusa".

No intuito de complementar e robustecer ainda mais o modelo concentrado de controle de constitucionalidade no Brasil houve a promulgação das Leis $n^{\circ}$ 9.868/1999 e 9.882/1999, onde a primeira dispõe sobre a Ação Direta de Inconstitucionalidade - ADI que possibilita o exame de compatibilidade das normas, publicadas após o ano de 1988, em relação ao texto constitucional; a Ação Declaratória de Constitucionalidade, que possui o objeto de confirmar a constitucionalidade de uma norma, para que não seja debatida em outra demanda; ou a Ação Direta de Constitucionalidade por Omissão - ADO, que proporciona a declaração de inconstitucionalidade de uma omissão legislativa, intencionando a concretizar o dispositivo constitucional. A segunda lei, por seu turno, prescreve a Arguição de Descumprimento de Preceito Fundamental - ADPF, norteada a recompor ou inibir a ofensa a algum preceito constitucional.

Portanto, tem-se que o sistema concentrado salienta ser o mais conveniente para dinamizar a Suprema Corte, de forma a minimizar a quantidade de demandas de interesse inter partes. Tal modelo com as ações constitucionais adequadas ambiciona aliviar o Tribunal de uma acentuada averiguação de temáticas de interesse coletivo.

\section{ARGUIÇÃO DE DESCUMPRIMENTO DE PRECEITO FUNDAMENTAL NO SISTEMA JURÍDICO PÁTRIO}

A Emenda Constitucional 3/93 introduziu o $§ 1 .^{\circ}$ ao art. 102 da CF/1988, que somente designou a competência do Supremo Tribunal Federal para deliberar sobre a ADPF, e foi necessária a edição de uma legislação específica para que pudessem emanar seus abrangentes efeitos, até que foi promulgada a lei $n^{\circ} 9.882 / 1999$, que estabeleceu os contornos 
da referida ação. Antes da elaboração da norma, a ADPF era um instrumento constitucional com eficácia limitada ou diminuída, precisando de um amparo legal para a aquisição de uma efetividade. Em seu início, a trivialização do instituto era bastante temida, motivo pelo qual o STF rejeitou diversas ADPFs antes da publicação da referida lei. (BARROSO, 2012, p. 210)

Muitos projetos de lei foram aventados, a revisão constitucional de 1993 debateu especialmente a plausibilidade de elaborar um incidente de inconstitucionalidade no país e surgiu um impasse que justamente abordava a necessidade da ADPF ser disciplinada por emenda constitucional. Streck (2019, p. 529) afirma que tal instituto é "inovador na história constitucional brasileira, sem qualquer precedente nas Constituições anteriores”. Esse dispositivo transformou notadamente o modelo nacional de controle de constitucionalidade, à medida que propiciou o adiantamento de deliberações sobre contendas constitucionais relevantes que demorariam anos por outra via.

Também cabe à ADPF a possibilidade de ser empregada para solucionar conflito expressivo sobre a validade do direito ordinário pré-constitucional em face da Carta de 1988. A repercussão vinculante e a eficácia erga omnes das decisões exprimidas em tais demandas denotam segurança para especificar o juízo sobre a legitimidade ou a ilegitimidade de atos de mesmo teor, produzidos pelas administrações municipais.

A ADPF integra a categoria concentrada de constitucionalidade, em complementação à $\mathrm{ADC}$ e $\mathrm{ADI}$ e compreende o intento de remover ou restaurar o dano a preceito fundamental resultante de atos do Poder Público, assim como dirimir desavença constitucional sobre norma ou preceito normativo federal, estadual ou municipal, incluindo-se os antecessores ao texto constitucional. O ministro Gilmar Mendes do STF declarou em um trecho da ADPD $n^{\circ}$ 33 - PA (BRASIL, 2005) a atuação do presente dispositivo constitucional como uma ferramenta de junção entre os modelos de controle de constitucionalidade no país: "[...] a ADPF configura modalidade de integração entre os modelos de perfil difuso e concentrado no Supremo Tribunal Federal".

Os doutrinadores de forma dominante (BARROSO, 2012, p. 211) verificam na Lei $\mathrm{n}^{\circ}$ 9.882/1999 a presença de duas espécies de ADPF, quais sejam: arguição autônoma e incidental. A primeira encontra fulcro no art. $1^{\circ}$, caput, "a arguição prevista no $\S 1^{\circ}$ do art. 102 da Constituição Federal será proposta perante o Supremo Tribunal Federal, e terá por objeto evitar ou reparar lesão a preceito fundamental, resultante de ato do Poder Público". Por sua 
vez, a incidental seria oriunda do mesmo dispositivo, no parágrafo único, acordado com o art. $6^{\circ}, \S 1^{\circ}$ do mesmo diploma, conforme a seguinte previsão:

Art. $1^{\circ}$ Parágrafo único. Caberá também arguição de descumprimento de preceito fundamental:

I - quando for relevante o fundamento da controvérsia constitucional sobre lei ou ato normativo federal, estadual ou municipal, incluídos os anteriores à Constituição.

$[\ldots]$

Art. $6^{\circ}, \S 1^{\circ}$. Se entender necessário, poderá o relator ouvir as partes nos processos que ensejaram a arguição, requisitar informações adicionais, designar perito ou comissão de peritos para que emita parecer sobre a questão, ou ainda, fixar data para declarações, em audiência pública, de pessoas com experiência e autoridade na matéria.

Segundo os estudos de Barroso (2012, p. 211) na autônoma, ademais do fundamento total da ausência de qualquer outra forma competente de resolver o prejudicial, reivindica-se: “(a) ameaça ou violação a preceito fundamental e (b) um ato estatal ou equiparável capaz de provocá-la." Refere-se, inegavelmente, a uma atuação similar às ações diretas previamente determinadas no texto constitucional, por meio do qual se eleva a domínio constitucional abstrato e concentrado da Suprema Corte. Assim, nota-se que a legitimação é idêntica a da ADI, todavia, o paradigma de verificação é mais adstrito, pois não é qualquer legislação, somente preceitos fundamentais. Ademais, o instrumento de compatibilidade também é mais abrangente, uma vez que não se restringe aos atos normativos e amplia-se aos três Poderes.

A doutrina de Gilmar Mendes sustenta que a arguição foi elaborada exatamente com o escopo de impulsionar a fiscalização de constitucionalidade concentrada, acrescentando na seara "questões que estavam excluídas de deliberação em sede do controle abstrato de normas" e, por conseguinte, conquistar um maior respaldo do texto constitucional, sobretudo dos preceitos fundamentais, embasamentos do sistema jurídico pátrio. (MENDES, 2015, p. 1061)

No que tange à tutela aferida pela ADPF, a Min. Rosa Weber aduz que é, especialmente, mais extensa que a do controle de constitucionalidade em si, expondo o seguinte:

Em certo sentido, a noção de descumprimento de um preceito constitucional é mais ampla do que a de inconstitucionalidade. De um lado, abrange a lesão à Constituição resultante de "ato do poder público" outro que não apenas a "lei ou ato normativo". De outro lado, quanto a estes últimos, alcança a impugnação de atos normativos que, embora validamente produzidos sob a égide de parâmetro constitucional pretérito, passaram a traduzir, à luz do paradigma vigente, efetivo e material descumprimento da Constituição. (STF, 2014) 
Em síntese, a ADPF demonstra explícita magnitude em virtude de seu funcionamento no controle de constitucionalidade nacional, como já mencionado, consolidando a verificação abstrata e alargando o protagonismo do Supremo Tribunal Federal, viabilizando que este atue essencialmente elucidando importantes litígios constitucionais revelados em instâncias ordinárias. Conforme o entendimento de Streck (2019, p. 532) é “[...] um plus normativo em relação aos institutos de proteção aos direitos fundamentais previstos no texto constitucional". Portanto, por intermédio da ADPF, pretende-se que o Poder Judiciário possa propiciar um resultado célere a tais questões, afastando um estado de indeterminação ocasionado por deliberações morosas e não uniformes.

\section{A AMPLITUDE DA EXPRESSÃO "PRECEITO FUNDAMENTAL"}

Como o texto constitucional de 1988 não indica o conceito preciso de preceitos fundamentais cumpre frisar que tal definição se oriente pelo acatamento de fatores ou fundamentos alcançados a partir daquilo que a Lei Maior, seja pela designação utilizada, seja pela relevância intrínseca, veio determinar como imprescindível. A compreensão, a priori, se eleva alicerçada no que seja viável estabelecer como direito fundamental, matéria cuja acepção parece estar conectada à interpretação de preceito fundamental, sendo, esta, de maior abrangência.

Em conformidade com as análises de Alexy, o elemento de fundamentalidade de um direito se concatena ao cumprimento de circunstâncias de interesse e carência, e mediante dois critérios. O primeiro é que certos proveitos ou privações possam e devam ser salvaguardados e reconhecidos pelo ordenamento jurídico. O referido autor expõe o exemplo de que não existe uma garantia a alguma coisa que não se permita obrigar pelo exclusivo direito, como seria o feito do direito ao amor. O segundo critério exige que o interesse seja tão imprescindível que aquela necessidade de tutela e promoção se fundamente com assente no ordenamento jurídico. Assim, vale ressaltar, segundo Alexy (2008, p. 48):

A fundamentalidade fundamenta, assim, a prioridade sobre todos os graus do
sistema jurídico, portanto, também perante o legislador. Um interesse ou uma
carência é, neste sentido, fundamental quando sua violação ou não satisfação
significa ou a morte ou sofrimento grave ou toca no núcleo essencial da autonomia.
Nisso são compreendidos não só os direitos de defesa liberais clássicos, mas, por
exemplo, também direitos sociais que visam ao asseguramento de um mínimo
existencial. Não são direitos do homem, segundo esse critério da fundamentalidade,
pelo contrário, por exemplo, o direito garantido no art. $7 .^{\circ}$, VIII, da CF/1988, a um 
décimo terceiro salário mensal ou a garantia, lá minutada no art. $230, \S 2 .^{\circ}$, do uso livre dos meios de circulação públicos urbanos para maiores de 65 anos.

O desfecho da alusão exposta enseja margem ao posicionamento de que existem inúmeras outras eventualidades contidas no texto constitucional de 1988 que também não poderiam ser apreciadas segundo o referido critério da fundamentalidade, como é o caso dos direitos primordiais ao indivíduo, em que pese a disposição, de boa parte destes, no Título II da $\mathrm{CF} / 88$, onde são catalogados os direitos e as garantias fundamentais.

Assim, consoante o entendimento de Almeida (2015, p. 101) "nem mesmo os mais renomados doutrinadores conseguem definir com exatidão o que vem a ser preceito fundamental, o que será encargo dos operadores do Direito.” A Lei no 9.882/1999, que ordenou a matéria, também não delimitou, de modo patente, a significação de preceito fundamental, isto é, tal padronização legislativa em muito pouco auxiliou para o aclaramento dos delineamentos do instituto, conservando, desse modo, a exiguidade de uniformidade, sendo também desdobrada à doutrina.

Para tanto, a construção limitada da concepção tem permanecido de acordo com a visão dos integrantes da Suprema Corte, ante o ambiente doutrinário e jurisprudencial contemplado para a estruturação e o embasamento. A omissão legislativa, impulsionadora da desarmonia sobre a definição e o preceito fundamental, tem sido assentada como benéfica na construção das decisões reiteradas dos tribunais, pois, para Almeida (2015, p. 25):

O legislador agiu bem ao não arrolar taxativamente quais, dentre os dispositivos
constitucionais, devem ser considerados como preceitos fundamentais. Ao valer-se
de um conceito jurídico indeterminado, a lei conferiu uma maleabilidade maior à
jurisprudência, que poderá acomodar com mais facilidade mudanças no mundo dos
fatos, bem como a interpretação evolutiva da Constituição. Caberá, ao Supremo
Tribunal Federal, definir tal conceito, sempre baseando-se na consideração do dado
axiológico subjacente ao ordenamento constitucional.

Barroso (2012, p. 213) defende a ideia que é uma totalidade de proposições constitucionais abrangendo deliberações no tocante à formação do Estado, à enumeração dos direitos e garantias fundamentais e às designadas normas sensíveis. Na ADPF no 33 - PA o relator, o ministro Gilmar Mendes, descreveu o preceito fundamental como sendo "direitos e garantias individuais, cláusulas pétreas, princípios sensíveis: sua interpretação, vinculação com outros princípios e garantia de eternidade”. (BRASIL, 2005)

No intuito de especificar uma noção de preceito fundamental, resta nítido o perigo de reduzir a sua dimensão ou de excedê-la, tornando as duas opções precárias. Por ter um 
conteúdo ainda aberto e uma constituição contínua pela jurisprudência e doutrina, prevalece a plausibilidade do conflito ante sua propositura. Algumas ADPFs não têm obtido o reconhecimento pelo STF por não preencherem os requisitos do conceito de preceito fundamental e outras têm sido por intermédio do princípio da fungibilidade convertidas posteriormente em ADI ou ADO, diminuindo, assim, a possibilidade de oposição.

Portanto, em consequência do explicitado, percebe-se que não existe definição uníssona de preceito fundamental, podendo ocasionar o surgimento de precedentes à discricionariedade para o juiz na sua deliberação. A amplitude da ordenação normativa de preceitos fundamentais é realizada de maneira paulatina pela doutrina e jurisprudência brasileiras, cabendo à Suprema Corte pronunciar-se sobre cada casuística em concreto. Conserva-se, dessa forma, a expectativa de conflito ante seu pleito, embora, gradualmente, o elenco exemplificativo do que seja preceito fundamental vem se avultando, mitigando, assim, a viabilidade de discórdias.

\section{ANÁlise DA ADPF 635 ANTE AO CONTEXTO PANDÊMICO PROPICIADO PELO NOVO CORONAVÍRUS}

O elevado número de mortes de moradores das regiões carentes do Rio de Janeiro, sobretudo a morte de menores, impulsionou a proposição da ADPF $n^{\circ} 635$ em novembro de 2019, através do Partido Socialista Brasileiro. A mencionada ação descortinou o agravamento da letalidade policial no Rio de Janeiro, visivelmente em âmbitos periféricos. Por conseguinte, o que se eleva é a falha na gestão das políticas públicas de segurança, cujos reflexos negativos se estendem por toda a sociedade mesmo durante a pandemia.

A fim de elevar o entendimento, cumpre evidenciar parte da supracitada decisão:

EMENTA: REFERENDO EM MEDIDA INCIDENTAL EM ARGUIÇÃO DE DESCUMPRIMENTO DE PRECEITO FUNDAMENTAL. REALIZAÇÃO DE OPERAÇÕES POLICIAIS NAS COMUNIDADES DO RIO DE JANEIRO DURANTE A PANDEMIA MUNDIAL. MORA DO ESTADO NO CUMPRIMENTO DE DECISÃO DA CORTE INTERAMERICANA DE DIREITOS HUMANOS. PLAUSIBILIDADE JURÍDICA.CONTEXTO FÁTICO EM QUE OS MORADORES PERMANECEM MAIS TEMPO EM CASA. RELATOS DE OPERAÇÕES QUE REPETEM O PADRÃO DE VIOLAÇÃO JÁ RECONHECIDO PELA CORTE INTERAMERICANA. PERICULUM IN MORA. CONCESSÃO DA MEDIDA. 1. A mora no cumprimento de determinação exarada pela Corte Interamericana de Direitos Humanos é fundamento que empresta plausibilidade à tese segundo a qual o Estado do Rio de Janeiro falha em promover políticas públicas de redução da letalidade policial. 2. A permanência em casa dos 
moradores das comunidades do Rio de Janeiro em decorrência da pandemia internacional, assim como os relatos de novas operações que, aparentemente, repetem os padrões de violações anteriores, fundamentam o receio de que a medida, caso concedida apenas ao fim do processo, seja ineficaz. 3. Medida cautelar deferida para determinar: (i) que, sob pena de responsabilização civil e criminal, não se realizem operações policiais em comunidades do Rio de Janeiro durante a epidemia do COVID-19, salvo em hipóteses absolutamente excepcionais, que devem ser devidamente justificadas por escrito pela autoridade competente, com a comunicação imediata ao Ministério Público do Estado do Rio de Janeiro responsável pelo controle externo da atividade policial; e (ii) que, nos casos extraordinários de realização dessas operações durante a pandemia, sejam adotados cuidados excepcionais, devidamente identificados por escrito pela autoridade competente, para não colocar em risco ainda maior população, a prestação de serviços públicos sanitários e o desempenho de atividades de ajuda humanitária. (ADPF 635 MC-TPI-Ref, rel. min. Edson Fachin, P, j. 05/08/2020, DJE 267 de 09/11/2020)

Na decisão do Ministro Fachin a ponderação é realizada sobre o direito à integridade corporal e à vida, ao indagar até que ponto a utilização da força letal pode alcançar. Em conformidade com o item 9 dos Princípios Básicos das Nações Unidas para o Uso da Força e de Armamentos Oficiais da Justiça, a utilização letal e intencional de armas apenas pode ser realizada em situações em que seja imprescindível para a proteção da vida do agente ou de terceiros, sendo essencial que o agente avise, previamente, sobre o uso do objeto e possua pleno entendimento sobre os riscos nos quais incide. (SILVA; BARROS, 2020, p. 107)

Verifica-se, ainda, com a decisão de Fachin, a determinação de uma medida preliminar, onde, antes de ser realizado o chamamento das forças de segurança, é necessária a elaboração de um documento pela autoridade policial, assim como o direcionamento de uma informação ao MP-RJ. Nesse diapasão, o relator da ADPF nº 635, Edson Fachin (2020), aferiu em seu voto que:

\footnotetext{
Embora, em alguns momentos, pareça que o objetivo é questionar a "política de segurança pública", o pedido feito na ADPF é especificamente voltado para a adoção de um plano de redução da letalidade policial. É, portanto, em relação à omissão do controle da utilização da força pelo Estado do Rio de Janeiro que se volta a presente arguição, explicou.
}

Para o referido Ministro do STF, os casos ocorridos nos últimos anos no Rio de Janeiro tornam mais preocupantes as informações reveladas sobre a atuação do Estado nos bairros periféricos. Fachin mencionou o lamentável caso do menino João Pedro, que foi alvejado dentro de sua própria casa durante uma operação das Polícias Civil e Federal em São Gonçalo, Rio de Janeiro. (BRASIL, 2020)

Assim, mesmo que os fatos devam ser analisados em sua completude, de acordo com o Ministro, "nada justifica que uma criança de 14 anos de idade seja alvejada mais de setenta 
vezes." A situação exposta exprime a necessidade de mais celeridade na reestruturação da política de segurança pública, de maneira a materializar uma ação policial mais eficaz e menos violenta. (BRASIL, 2020)

Assim, a partir das pesquisas realizadas pelo Grupo de Estudos dos Novos Legalismos, da Universidade Federal Fluminense, sendo usados dados atualizados sobre as operações policiais em bairros carentes no Rio de Janeiro, efetuou-se um estudo para analisar, estatisticamente, as repercussões da medida cautelar da ADPF 635. Dessa forma, a pesquisa de Hirata et. al (2020, p. 13) evidencia que:

Como forma de associar todos esses resultados positivos na preservação de vidas
decorrentes da Decisão liminar do Ministro Edson Fachin ao primeiro item deste
relatório, cujos resultados mostraram que as operações são um método ineficaz no
controle da criminalidade, procuramos comparar os dados criminais durante o
período do mês de junho de 2020 com a média de igual período entre 2007-2019.
Segundo dados oficiais compilados pelo ISP-RJ, a diminuição das operações
policiais e a consequente redução no número de mortos e feridos em operações
policiais foi acompanhada de uma diminuição da criminalidade.

Na pesquisa realizada por Hirata et. al., entre 05 e 19 de junho de 2020 o estudo apontou a menor incidência de operações policiais desde 2007, alcançando uma diminuição de $68,3 \%$ no tocante à média dos anos antecessores. Por conseguinte, também se constatou uma redução no índice de óbitos, sendo essa de 75,5\% em comparação ao período de 2007 e 2019; e de 85,8\% em relação à estimativa para 2020. (HIRATA et. al., 2020, p. 4)

Percebe-se que o direito à vida, disciplinado no caput do art. $5^{\circ}$ da $\mathrm{CF} / 88$, proporcionado a todos os indivíduos, é um direito fundamental, do qual advém todos os demais. Ressalta-se que não haveria justificativa em garantir outros bens jurídicos se a vida não fosse protegida e é exatamente pelo respeito a tal preceito que o texto constitucional estabelece que a segurança pública, assim como a saúde, são obrigações do Estado. Tutelar a vida compreende não somente em propiciar a existência do indivíduo, mas também proteger a sua integridade moral e física, através de políticas de segurança pública, que apenas serão eficazes, quando direcionadas em proposições conscientes e pensadas. (BRASIL, 2020)

Portanto, a pandemia gerada pelo novo coronavírus impulsionou a edificação de novas premissas - como é o caso da ADPF 635 - para combater uma complexa questão da sociedade carioca e, simultaneamente, abrandou o fundamento daqueles que assentam um combate direto às organizações criminosas. 


\section{CONSIDERAÇÕES FINAIS}

Com a realização do presente estudo, verificou-se que a Constituição Federal de 1988 é uma norma essencial, onde todo o arcabouço jurídico deve partilhar com ela uma relação de conformidade, caso contrário, será configurado como nulo. A inconstitucionalidade se exprime na divergência da temática de determinada norma ou de sua técnica de construção com o texto constitucional de 1988. Assim, observou-se que o controle de constitucionalidade no país é misto e divide-se em dois modelos: concentrado e difuso e, no Brasil, nota-se uma propensão para o sistema concentrado, sem dano da jurisdição difusa, ante ao exercício da ADI, ADC, ADIO e da ADPF.

A ADPF caracteriza-se como uma ação constitucional, norteada a tutelar objetiva e abstratamente, no modelo concentrado, qualquer ato concreto, não precisamente normativo e decorrente do poder público, desde que seja revelada divergência com o texto constitucional, exposto preceito que advenha de valor que a $\mathrm{CF} / 88$ considere fundamental, como é o caso do direito à vida, à saúde, à integridade física dos indivíduos etc.

Ainda, o corrente trabalho apontou que a ADPF se elevou para eliminar algumas lacunas no modelo de controle de concentrado de constitucionalidade existente no Brasil, almejando a possibilidade de exame pela Suprema Corte de alguns temas, como as normas pré-constitucionais e municipais, que anteriormente apenas eram possíveis por outras ações do controle difuso.

Portanto, a pesquisa se intencionou a responder o problema mencionado na introdução do presente artigo e obteve como resultados, através da análise jurisprudencial da ADPF 635 e dos estudos de Hirata et. al. (2020), que a referida decisão do ministro do STF contribuiu para a proteção dos direitos fundamentais dos moradores de comunidades carentes ao promover efeitos benéficos no tocante à letalidade policial e à violência no Rio de Janeiro, sendo depreendido pelos autores, com base em dados estatísticos, que se alcançou uma redução no número de óbitos e de feridos em operações policiais no Rio de Janeiro no período das medidas sanitárias determinadas, como também uma diminuição da criminalidade na sociedade carioca.

\section{REFERÊNCIAS}


ALEXY, Robert. Constitucionalismo discursivo. 2. ed. rev. trad. Luís Afonso Heck. Porto Alegre: Livraria do Advogado, 2008.

ALMEIDA, Deyse Coelho de. O que são os preceitos fundamentais garantidos pela Arguição Descumprimento de Preceito Fundamental (ADPF)? A amplitude do conceito gera, para o magistrado, uma discricionariedade na precisão do que sejam preceitos fundamentais? 2015. Disponível em: https://jus.com.br/artigos/6237/o-que-saoos-preceitosfundamentais-garantidos-pela-arguicao-descumprimento-de-preceitofundamental-adpf. Acesso em: 31 mai. 2021.

BARROSO, Luís Roberto. O controle de constitucionalidade no direito brasileiro. 6 ed. rev. e atual. São Paulo: Saraiva, 2012.

BRASIL. Constituição da República Federativa do Brasil, promulgada em 5 de outubro de 1988. Disponível em:

www.planalto.gov.br/ccivil_03/constituicao/ConstituicaoCompilado.htm. Acesso em: 28 mai. 2021.

BRASIL. Lei $\mathbf{n}^{0}$ 9.882, de 3 de dezembro de 1999. Dispõe sobre o processo e julgamento da argüição de descumprimento de preceito fundamental, nos termos do $\S 1$ o do art. 102 da Constituição Federal. Disponível em: http://www.planalto.gov.br/ccivil_03/leis/19882.htm. Acesso em: 30 mai. 2021.

BRASIL. Lei no 9.868, de 10 de novembro de 1999. Dispõe sobre o processo e julgamento da ação direta de inconstitucionalidade e da ação declaratória de constitucionalidade perante o Supremo Tribunal Federal. Disponível em:

http://www.planalto.gov.br/ccivil_03/leis/19868.htm. Acesso em: 30 mai. 2021.

BRASIL. Supremo Tribunal de Federal. Arguição de Descumprimento de Preceito

Fundamental 33 PA. Relator: Min. Gilmar Mendes. Data de julgamento: 07/12/2005.

Tribunal Pleno. Disponível em:

https://redir.stf.jus.br/paginadorpub/paginador.jsp?docTP=AC\&docID=388700. Acesso em: 11 jun. 2021.

BRASIL. Supremo Tribunal de Federal. Arguição de Descumprimento de Preceito Fundamental 97 PA. Relator: Min. Rosa Weber. Data de julgamento: 21/08/2014. Tribunal Pleno. Disponível em: https://stf.jusbrasil.com.br/jurisprudencia/25342189/arguicao-dedescumprimento-de-preceito-fundamental-adpf-97-pa-stf. Acesso em: 31 mai. 2021

BRASIL. Supremo Tribunal Federal. Arguição de Descumprimento de Preceito Fundamental 635 RJ. Rio de Janeiro. Min. relator Edson Fachin. 2020. Disponível em: http://www.stf.jus.br/arquivo/cms/noticiaNoticiaStf/anexo/ADPF635DECISaO5DEJUNHOD E20202.pdf. Acesso em 28 mai. 2021.

CUNHA JÚNIOR, Dirley da. Controle judicial das omissões do poder público. São Paulo: Saraiva, 2004. 
FAVOREU, Louis. As cortes constitucionais. Trad. Dunia Marinho Silva. São Paulo: Landy, 2004.

HIRATA, Daniel Veloso; GRILLO, Carolina Christoph; DIRK, Renato. Operações policiais e ocorrências criminais: por um debate público qualificado. Grupo de Estudos dos Novos Iegalismos - GENI. Rio de Janeiro. 2020.

MENDES, Gilmar Ferreira. Curso de direito constitucional. $10^{a}$ ed. rev. e atual. São Paulo: Saraiva, 2015.

MORAES, Alexandre de. Direito Constitucional. 33. ed. rev. e atual. São Paulo: Atlas, 2017.

NOVELINO, Marcelo. Leituras complementares de direito constitucional: Controle de constitucionalidade e hermenêutica constitucional. Salvador: JusPodivm, 2008.

RAMOS, Elival da Silva. Controle de constitucionalidade no Brasil: perspectivas de evolução. São Paulo: Saraiva, 2010.

SILVA, Isabela Inês Bernardino de Sousa; BARROS, Isabela Maria Pereira Paes de.

Necropolítica nas periferias: um estudo sobre a limitação das operações policiais nas favelas do Rio de Janeiro durante a pandemia. vol. 8. $\mathrm{N}^{\mathrm{o}}$ 2. Revista Transgressões: ciências criminais em debate. 2020.

STRECK, Lenio Luiz. Jurisdição constitucional. 6 ed. Rio de Janeiro: Forense, 2019. 